\title{
EXTREME FORMS OF EVALUATION IN LEARNING ENCOUNTERS
}

\author{
Laura Cano Mora \\ Universitat de València \\ 1.canomora@gmail.com
}

\section{AbStract}

This paper examines the use of hyperbole as a recurrent form of feedback in classroom interaction. It aims to show that hyperbole is a language universal that cannot only be found in learning encounters but also plays an important part in their IRF exchange system. The data examined are naturally-occurring spoken learning encounters extracted from the BNC and analysed within the constraints of placement, sequencing and turntaking of discourse analysis. The results seem to suggest that hyperbole embodies one of the most distinctive features of teaching exchanges: it mainly occurs in the follow-up move and is mainly used to evaluate students' responses positively. This evaluative teachers' feedback move is a feature that clearly distinguishes classroom interaction from natural conversation.

KEY WORDS: hyperbole, evaluation, teaching exchange, discourse analysis and corpus linguistics.

\section{RESUMEN}

El presente artículo analiza el uso de la hipérbole como forma habitual de feedback en el aula. El objetivo es demostrar que la hipérbole, característica universal del lenguaje, no sólo se da en el contexto educativo sino que además juega un papel importante en el denominado intercambio IRF. El corpus analizado consta de interacciones reales en el 
aula extraídas del BNC y analizadas desde la perspectiva del análisis del discurso. Los resultados apuntan a que la hipérbole representa una de las características definitorias del intercambio educativo: con frecuencia se localiza dentro del llamado follow-up move y su función principal es evaluar positivamente las respuestas de los alumnos. Precisamente ésta es una de las características que distingue la interacción en el aula del habla cotidiana.

Palabras Clave: hipérbole, evaluación, intercambio educativo, análisis del discurso y lingüística de corpus.

\section{INTRODUCTION}

Although figurative language has been studied for more than two millennia, figures of speech have until recently been disregarded or relegated to the field of literary criticism, where they have been attributed a purely ornamental or aesthetic value. Over the last thirty years there has been a renewed interest in figurative language in other disciplines such as cognitive psychology, cognitive semantics and Relevance Theory. Some progress has been made in the study of the so-called master tropes: metaphor and irony, and to a lesser extent, metonymy. But with a few exceptions, most of this interest has been directed at explaining how figures are comprehended, given their non-literal nature. Since research has mainly focused on reception and understanding, it is not surprising that nowadays a crucial limitation in figurative language theories is the production of figures.

Only in the last decades have cognitive psychologists become interested in the pragmatic functions of non-literal forms, but although the literature on the discourse goals fulfilled by irony, and to a lesser extent, metaphor, is extensive, the study of other figures has almost systematically been neglected. Rarely has their placement within the conversational framework been studied to date.

This paper examines the production of hyperbole in learning encounters by combining pragmatic and discourse-analytical methods with a corpus-based approach. Special attention is devoted to the function and placement of this figure in classroom interaction. It aims to give an insight into the use of hyperbole as a recurrent form of positive feedback to assess students' responses in class.

\section{StUdies ON HyPERBole}

Although since late antiquity hyperbole has been one of the many figures of speech discussed within the general framework of rhetoric, the emphasis has primarily been laid on defining, classifying and illustrating hyperbole, often from literary masterpieces. In contemporary language theories the scarcity of studies addressing hyperbole is most notable, probably because in other disciplines it has generally been considered a classic trope whose study belongs to that of rhetoric. Most of the empirical work on exaggeration has involved comparisons of frequency and use in different cultures (e.g. Spitzbardt, 1963; Cohen, 1987; Edelman et al., 1989). Apart from these cross-cultural studies, most interest in hyperbole can be found within studies of verbal irony or theories of humour and focused on the process of understanding. 
Despite its ubiquity, the study of hyperbole has tended to be neglected by figurative language researchers. Kreuz et al. (1996), after studying eight non-literal language forms in a corpus of contemporary short stories, adduce empirical evidence of its pervasiveness by showing that after metaphor hyperbole is the most common trope. The importance of hyperbole becomes even clearer after an inspection of the co-occurrence matrix in the aforesaid study. These scholars also demonstrated that exaggeration is by far the trope that most often co-occurs with other figures, particularly with metaphor. It was involved in almost eighty percent of the cases of co-occurrence and it interacted with every other figure with the exception of its logical opposite, understatement.

Within the production process, little research has been conducted on the pragmatic functions of hyperbole, probably as a result of the intensive research effort on comprehension. Although some of the functions that hyperbole fulfils in discourse have been identified, especially humour and evaluation, the bulk of research has mainly been restricted to their identification.

During late antiquity and the Middle Ages, periods in which figural rhetoric is said to have flourished, rhetoric was equated with persuasive discourse. Thus, hyperbole was associated with manipulation, as a strategy to bring listeners into the perspective of the speaker in a powerful way (Swartz, 1976). The Renaissance, however, marks a change in emphasis from the canon of argumentation to the canon of invention, with rhetoric becoming primarily figural. During this period ornamentation acquires unprecedented importance and so rhetoric is restricted to «Elocution», the use of tropes and figures, commonly considered forms of verbal ornament (Poster, 2000: 120). Since then, hyperbole, like many other figures, has traditionally been regarded as an ornamental device to produce stylistic or aesthetic effects.

Nowadays, most interest in the pragmatic functions of hyperbole can be found in the field of psycholinguistics and embedded within studies of other figures, especially irony and understatement, to contrast the extent to which they fulfil similar functions (e.g. Roberts and Kreuz, 1994; Sell et al., 1997; Colston and Keller, 1998; Colston and O'Brien, 2000). Roberts and Kreuz (1994), for example, point out that the most salient functions for hyperbole are to be humorous, to emphasise, to add interest and to clarify. However, they make it clear that these functions are not exclusive to hyperbole since they are weakly shared by understatement too. Similarly, Sell et al. (1997) conducted an experiment addressing parents' use of non-literal language with pre-school children and showed that common functions fulfilled by hyperbole, like rhetorical questions and idioms, were clarification, emphasis, positive evaluation and maintaining the child's focus.

\section{LEARNING ENCOUNTERS}

In linguistics, the last thirty years have seen interesting attempts at defining and describing genre. The problem is that there is no general consensus concerning its definition and there is often considerable theoretical disagreement about the definition of specific genres too. For Swales (1990: 58), who stands out as one of the most important figures in genre theory, the three key elements are: «discourse communities», «communicative 
purpose» and «task». He defines genre as a type of communicative event comprising the discourse itself, its participants, the role of that discourse and its context of use. Indeed, most genre analysts regard communicative purpose as the principal criterion for genre identification and definition.

There are spoken and written genres, but while the literature on written genres is extensive, speech genres have rarely been discussed. Genre, says McCarthy (1998), is an ill-defined notion in the study of spoken language in general and apart from well-studied genres such as service encounters and narratives, many of the everyday forms of talk we engage in remain unclassified in generic terms.

This paper focuses on learning encounters. They have been defined as «language in use in the context of institutionalised and informal learning» (Carter and McCarthy, 1997: 10) and usually occur within the educational context in the form of lessons, tutorials, lectures, conferences, workshops and so forth. In one of the best known accounts of classroom interaction, Sinclair and Coulthard (1975) developed a hierarchical model consisting of five different levels in the structure of a lesson: (1) lesson, (2) transaction, (3) exchange, (4) move and (5) act. The element of structure that is most clearly defined is that of the teaching exchange, which typically has three phases: an initiating move, a responding move and a feedback or follow-up move. This is what discourse analysts have termed an IRF exchange.

Initiation (I) an utterance, mainly teacher-led

Response (R) mainly a pupil response/reply

Feedback (F) mainly a follow-up comment by the teacher which also often evaluates or rephrases or expands what the pupil has said. (Carter and McCarthy, 1997: 124)

This BNC fragment is exemplary of IRF classroom exchanges:

(1) Text FY9

Teacher: How far is erm three and half hours?

Initiation

Student: A hundred and fifty miles.

Response

Teacher: That was very good. That was brilliant, yeah. Feedback

In the tripartite exchange system, each move can be realised by means of various kinds of acts -the smallest unit in the discourse system. For example, in the extract above the follow-up move is performed by means of forms of evaluation (that was very good and that was brilliant) and a form of acceptance (yeah).

Much formal teaching is characterised by IRF exchanges. However there are variations on this basic structure. As Stubbs (1983: 133) notes, a teacher-elicit exchange, where the teacher elicits a verbal response from the pupil, has the full IRF structure. A teacher-direct exchange, in which the teacher directs a pupil to do something, has the structure $\operatorname{IR}(\mathrm{F})$, where $\mathrm{R}$ is a non-verbal response. A teacher-inform exchange in which a teacher conveys propositional information as in lecturing and pupils may or may not respond has the structure $\mathrm{I}(\mathrm{R})$. A checking exchange, where the teacher does not know the answer to his/her initiation question, has the structure IR(F).

Learning encounters are often characterised by marked differences in the participants' speaking styles. Teachers have more power than students. This explains that in our data, although outnumbered by students, teachers take most turns, defined as «every 
instance of talk between two subsequent speaker changes» (Strässler, 1982: 75). The teacher also asks most of the questions, with students' contributions mainly taking the form of answers to those questions. It is generally assumed that students act as responders, not as initiators of exchanges. Teachers often ask pseudo-questions to which they already know the answer and they evaluate pupils' responses in line with their own expectations (Stubbs, 1996). Besides, teachers' turns are longer than the students' because teachers tend to use complete, fully-formed clauses, whereas students' contributions are usually short and elliptical and can only be understood in the context of teachers' utterances (Carter and McCarthy, 1997). The aim of teacher's discourse is to monitor classroom talk and that is achieved through eight main functions: attracting or showing attention, controlling students' amount of speech, checking or confirming understanding, summarising, defining, editing, correcting and specifying topic (Stubbs, 1983).

\section{Methodology}

\subsection{Aim}

This paper aims at examining the use of hyperboles in learning encounters in order to determine their placement pattern within the teaching exchange, for which special attention will be devoted to the interactive organisation of conversation as described by discourse analysts, and more importantly, to determine their role or function within the teaching process.

\subsection{Corpus description}

In order to examine hyperbole, a corpus of naturally-occurring learning encounters taken from the British National Corpus (BNC, henceforth) was subjected to analysis. The BNC is a collection of samples, totalling over 100 million words, of modern British English, both spoken and written, stored in electronic form, although for this study only transcribed spoken material was examined.

The focus was on oral discourse since most research on hyperbole has been conducted in written texts. This choice was aimed at counterbalancing the lack of studies addressing hyperbole in authentic everyday talk since rhetorical scholars have often listed striking examples from earlier writers, especially poets, to illustrate figures of speech. On the other hand, the bulk of psycholinguistic research over the last thirty years has utilised artificial texts as stimulus materials. Although numerous scholars have stressed that hyperbole is a regular feature of everyday speech (e.g. Fontanier, 1968; Ravazzoli, 1978; Falk, 1990), very little research exists into everyday spoken hyperbole.

Ten learning encounters, totalling 57,914 words, were examined. They were chosen at random, while every effort was made not to repeat subjects and to avoid literature lessons since they obviously contain more figurative language than average. The texts include a wide range of subjects, namely Maths, French, English, Cooking, Science, Religious Studies, Archaeology, Chemistry, Word-processing and Art. The number of students varies depending on the character of the learning encounter, whether institutional (e.g. lectures, lessons) or more informal (e.g. tutorials). The age of the students ranges from 10 to 20 . The reason why seminars and some lectures were avoided is because talk 
here takes the form of a platform monologue and there is little or no interaction since the teacher is given exclusive claim to the floor.

Table 1. Defining features of the BNC learning encounters examined

\begin{tabular}{|c|c|c|c|c|}
\hline BNC Text & Words & Subject & Age of students & Lesson type \\
\hline FY9 & 5,775 & GCSE Maths tutorial lesson & 16 & Individual \\
JA8 & 2,373 & French conversation class & 9 & Collective \\
F7N & 2,058 & Remedial English lesson & 11 & Collective \\
F8A & 3,160 & Lecture on food & College & Collective \\
FMB & 3,288 & Science lesson & 14 & Collective \\
F7R & 6,064 & Religious Studies lesson & 11 & Collective \\
FML & 7,157 & Discussion on archaeology & 20 & Collective \\
KLW & 14,553 & Word-processing tutorial & 10 & Individual \\
FM5 & 12,889 & GSCE chemistry tutorial lesson & 16 & Individual \\
F75 & 597 & Mounting a picture lesson & High School & Collective \\
\hline
\end{tabular}

One of the problems encountered was the impossibility of analysing non-verbal communication in the BNC texts. As Tsui (1994) notes, in face-to-face interaction, the follow-up move is often realised by non-verbal means such as a nod, a smile and so forth. Similarly, some responses are actions rather than linguistic replies. Since actions and gestures are rarely recorded in transcriptions, at times the BNC might give the illusion that the follow-up move or response move is absent.

\subsection{Items for analysis: definition of hyperbole}

As for the object of study, traditional definitions of hyperbole usually respond to the etymology of the term in Greek and Latin, which refers to the notions of excess and exaggeration. However, these definitions are too generic and do not clearly distinguish hyperbole from other related figures of disproportion. Irony, for example, may also involve an element of extremity in saying the opposite of what the speaker means. More recent definitions of hyperbole tend to be goal-oriented and focus on the use of this figure for emphasis or for effect (e.g. humour). The definition of hyperbole adopted here is as follows:

Hyperbole is a figure whereby the quantity or quality of an objective fact is, whether purposely or inadvertently, subjectively inflated or deflated in varying degrees but always to excess in a conventional or creative utterance which listeners do not normally interpret literally or perceive as a lie. (Cano, 2011: 38).

\subsection{Procedure}

The theoretical framework adopted for the present study relies heavily on a pragmatic and discourse-analytical approach and benefits from the tools that the two disciplines offer for the description of hyperbolic speech in interaction. In this sense, Hutchby and Drew (1995: 182) have noted that research in both discourse analysis and pragmatics contributes to the development of a naturalistic, observation-based empirical science of actual verbal behaviour. 
Exaggeration cannot be understood in isolation or in decontextualised situations. Context plays a central role in the perception of hyperbole. For this reason, it has been argued that this figure cannot be studied out of the realm of pragmatics, broadly defined as the study of meaning in context. Contextual information, not only linguistic but also situational and referential, allows us to determine whether the utterance must be interpreted hyperbolically or not. Hyperbole is a purely pragmatic phenomenon, since it is only the full context which can determine the presence of an exaggeration in discourse (Ravazzoli, 1978). Numerous scholars have stressed the crucial role that the context plays in hyperbole perception and assessment of degree of inflation (e.g. Zwicky and Sadock, 1975; Ravazzoli, 1978; Kreuz et al., 1998). Besides, contextual information helps to determine the pragmatic functions fulfilled by this figure of speech.

Discourse analysis pays attention not only to the function of individual utterances but also to how utterances combine to form larger discoursal units (Ellis, 1994). Discourse analysts are fundamentally looking for structure in conversation. They aim to describe rank-ordered structure beyond the sentence. An early interest within discourse analysis was classroom interaction. Studies of the features of teacher-student communication by Sinclair and Coulthard (1975), Coulthard (1977), Brazil et al. (1980) and other Birmingham-based scholars brought this field to the very centre of discourse analysis. In particular, Sinclair and Coulthard (1975) devised a descriptive framework for analysing interaction -using classroom data as a starting point- involving five descriptive units: act, move, exchange, transaction and lesson. These units are ordered in a hierarchical manner such that acts combine to form moves, moves combine to form exchanges, which in their turn combine to form transactions and transactions form lessons. This helps explain why this discipline is seen as a method for systematically describing the kinds of interaction that occur in classrooms.

On the other hand, this is a corpus-based study of hyperbole in learning encounters. One of the major benefits of using corpora is that «they allow researchers, teachers and learners to use great amounts of real data in their study of language instead of having to rely on intuitions and made-up examples» (Schmitt, 2000: 68). Corpus-based research grounds its theorising, say Aston and Burnard (1998), in empirical observation, rather than in appeals to linguistic intuition or expert knowledge. Besides, a major advantage of corpora is the automatic retrievability of context, so vital to interpret and recognise hyperbole and figurative language in general.

However, although this is a corpus-based study, the method of data sampling is nondeterministic. The object of study is not a particular hyperbolic word or expression, nor a specific word class or grammatical category. Rather, all instances of exaggeration included in the BNC texts analysed were examined. Whole conversations were scrutinised in search of hyperboles. This choice was motivated by the interactive nature of speech. In this sense Katz (1996: 2) emphasises that a crucial limitation in analyses based on isolated or decontextualised sentences, is that they «ignore the ecology in which we encounter and produce figurative language». 


\section{RESUlts AND DISCUSSION}

As for the results, 101 hyperboles were found in our data. Once identified, the turns containing forms of exaggeration were classified into initiation, response or follow-up moves. The table below illustrates the distribution of hyperbole into moves in the texts examined.

Table 2. Number and distribution of hyperboles into moves in the BNC data examined

\begin{tabular}{|c|c|c|c|c|c|c|}
\hline $\begin{array}{c}\text { BNC } \\
\text { Text }\end{array}$ & Subject & Words & Hyperboles $\rightarrow$ & Initiation & Response & $\begin{array}{c}\text { Follow- } \\
\text { up }\end{array}$ \\
\hline FY9 & Maths & 5,775 & 5 & 3 & - & 2 \\
JA8 & French & 2,373 & 2 & - & - & 2 \\
F7N & English & 2,058 & 5 & - & - & 5 \\
F8A & Cooking & 3,160 & 6 & 2 & 1 & 3 \\
FMB & Science & 3,288 & 2 & - & - & 2 \\
F7R & Religious Studies & 6,064 & 24 & 10 & 1 & 13 \\
FML & Archaeology & 7,157 & 22 & 10 & 4 & 8 \\
KLW & Word-processing & 14,553 & 17 & 2 & - & 15 \\
FM5 & Chemistry & 12,889 & 15 & 2 & 3 & 10 \\
F75 & Art lesson & 597 & 3 & 1 & - & 2 \\
\hline Total & 10 classes & 57,914 & 101 & 30 & 9 & 62 \\
\hline
\end{tabular}

As table 3 shows, 30 hyperboles occurred in the initiation move, which represents almost $30 \%$ of the hyperboles in the data examined. Only 9 feature in response moves, which accounts for approximately $9 \%$. However, the bulk of hyperboles, totalling 62, occurs in the follow-up or feedback move. That accounts for $61 \%$ of the items in our data, almost double the number of initiation moves. This means that hyperbole typically occurs in IRF exchanges -as opposed to other types of teaching exchange- and that the typical location of an exaggeration in classroom interaction is the follow-up or feedback move.

Table 3. Frequency and distribution of hyperboles into moves in the BNC texts

\begin{tabular}{|c|c|c|}
\hline Moves & Hyperbolic items & Percentage \\
\hline Initiation & 30 & $29.7 \%$ \\
Response & 9 & $8.9 \%$ \\
Follow-up & 62 & $61.3 \%$ \\
\hline
\end{tabular}

Once classified into moves, moves were further subdivided into acts, paying special attention to the function of exaggeration since Sinclair and Coulthard (1975) define acts as units characterised according to their local function in discourse. The results seem to suggest that hyperbole is mainly an evaluative figure of speech. Out of 101 hyperboles found in our data, 64 responded to evaluation. That represents $63.3 \%$ of the BNC items examined. This finding is very much in line with the results of our move analysis. Hyperbole was mainly found in feedback or follow-up moves because it fulfils the main function attributed to feedback, which is to evaluate the correctness of the student's reply.

Other functions fulfilled by exaggeration in our data were emphasis, expression of surprise, simplification, interest intensification, contrast of differences, humour, clarifi- 
cation and polite de-emphasis. However, their frequency in learning encounters, at least compared to evaluation, seems almost negligible. These functions were performed to a much lesser extent and often in conjunction with evaluation.

Table 4. Number, type and distribution of evaluative uses of hyperbole per move

\begin{tabular}{|c|c|c|c|}
\hline Moves & Evaluative $\rightarrow$ & Positive evaluation & Negative evaluation \\
\hline Initiation & 8 & 4 & 4 \\
Response & 2 & - & 2 \\
Follow-up & 54 & 49 & 5 \\
\hline Total & 64 & 53 & 11 \\
\hline
\end{tabular}

Since $63.3 \%$ of the items examined respond to evaluation, hyperbole needs to be viewed as a major evaluative mechanism in learning encounters. This is not surprising given that «instead of conveying factual information, hyperboles express speakers' attitude, emotional state and degree of involvement in what is being said» (Falk, 1990: 39).

As table 4 shows, hyperbole in learning encounters is evaluative but mainly in feedback or follow-up moves rather than responses or initiation moves. This may be explained by the fact that hyperbole is mostly used to evaluate the student's performance or answer. That can be described as the most prominent function of hyperbole in classroom interaction. Providing this evaluative third part is characteristic only of classroom exchanges. As Tsui (1994: 13) puts it: «We do not go around evaluating other people's responses- not if we want to keep friends». That is the main difference between followup moves in natural conversation and classroom exchanges.

Obviously, this evaluative function is twofold, since one can express both positive and negative opinions, emotions or attitudes. Thus, people may exaggerate to fulfil positive discourse goals, such as to compliment, congratulate, praise, express sympathy, approval, delight or some other form of positive affect. By contrast, negative evaluation is a form of subjective judgement whereby speakers attack, complain, condemn, criticise, express disapproval, antipathy or some other negative attitude. In our data, however, hyperbole is mainly used to convey positive evaluation. Of the evaluative hyperboles examined, $83 \%$ were positive while only $17 \%$ were negative. Teachers, therefore, can be said to resort to hyperbole to show approval rather than to condemn.

Only five negative evaluative follow-up moves were found in the learning encounters analysed. In turn, this means that very few examples of criticism directed to students or their responses appear in our data. Below there are two examples of negative evaluation conveyed through exaggeration in teachers' feedback moves. In the first excerpt what determines the evaluative force of the utterance is the negative import of the hyperbolic items. In the second, however, the precise negative attitude expressed can only be identified in the particular context.

(2) Text F75

Teacher: Kelly, you are once again doing it completely and utterly wrong. At the wrong place again. Kelly you have been using

Student: [inaudible response]

Teacher: Kelly, you've done it again. 
(3) Text FMB

Teacher: You forgot the first rule: put your hand up. Right, fluorine is the actual element, fluoride is the stuff that's in?

Student: Toothpaste.

Teacher: Toothpaste, very good. You never put your hand up. Right, CL.

Student: Please, sir is [...] chloride

As for positive hyperbolic forms in feedback moves, the most common exaggerations (with the number of occurrences in brackets) are: brilliant (20), great (9), excellent (7), lovely (7), wonderful (3), absolutely (2) and perfectly alright (1).

Since feedback moves often consist of several acts, hyperbole was usually found in combination with other types of acts in the BNC texts examined. In fact, hardly ever was exaggeration found in isolation within the follow-up move. Four different patterns featuring hyperbole can be clearly distinguished in our data.

Sometimes teachers repeated the students' answer or part of their answer preceded or followed by an exaggerated form of evaluation of the students' response. Let us take the fragments below by way of illustration.

(4) Text F7N

Teacher: Right, what's the next word?

Student: Share

Teacher: Share. What does «share» mean?

Student: You share out.

Teacher: You share out. Can you put that in a sentence?

Student: I like to share out my sweets.

Teacher: Oh, that's lovely. I like to share out my sweets.

(5) Text KLW

Teacher: So this is ten times one and this is ten times ten. We could cancel those out and we get

Student: One tenth

Teacher: One tenth, brilliant.

At other times hyperbolic acts within follow-up moves could be defined as instances of figurative paraphrase. Typically in our data a literal positive evaluation of the student's response precedes an exaggerated form of approval.

(6) Text FMB

Teacher: And I?

Student: Iodine.

Teacher: Very good, excellent.

(7) Text JA8

Teacher: so twenty-nine will be?

Student: vingt-neuf.

Teacher: You've got it well done. That's lovely.

At this point it is worth reflecting on the relationship between literal and hyperbolic expressions within the same turn or move, since it has typically been assumed that language is used figuratively when a literal expression would be inadequate. However, in our data, hyperbolic and literal evaluative remarks seem to extend and complement 
-rather than replace- each other, often through paraphrase. In other words, teachers do not normally use hyperbolic expressions in lieu of literal ones, but rather in addition to them. Thus, the conventional idea of exclusion between figurative and literal language needs some revision.

Repetition of sense is employed to ensure that listeners get across the force of the speaker's utterance, whether literal or figurative. Indeed, it has been argued that «a figurative expression, $E$, may be conjoined with an expression whose literal content is similar to the potential figurative effect of $E$ and no redundancy should result» (Sadock, 1993: 52-3). This notion of reiterability points to a reformulation or paraphrase of some preceding idea or propositional content, whether in literal or figurative terms. It should be mentioned, though, that compared to hyperbole, «literal paraphrases have less emphasis, are less vivid, less affectively tuned, and possess less variety of possible nuances of interpretation» (Cacciari, 1998: 143). That might explain why in the exchanges examined teachers finally resort to exaggeration after using literal comments.

Hyperbole also co-occurred with other hyperbolic evaluative descriptions within the same follow-up move, as exemplified below.

(8) Text FML

Museum guide: Why do you think they've got those little chips in them?

Student: To plaster over?

Museum guide: Plaster over, brilliant. Now that's a very important clue that you've spotted. Brilliant. Now what I want you to do. Now this is getting very exciting to me. I'm, I, this is the first time it's happened this way round that anybody's got ... That's the most subtle clue and somebody's spotted it. I think it's wonderful.

One of the most recurrent patterns in our data was the combination of hyperbole with a form of acceptance, such as okay, right, yes or yeah.

(9) Text FM5

Student: H C L plus N A O H is equal to N A C L

Teacher: Right, yeah.

Student: plus $\mathrm{H}$ two $\mathrm{O}$

Teacher: Right, great.

(10) Text F8A

Lecturer: Can you just check that we took down the following? I think that we actually just had time to talk through these and you didn't actually make notes.

Student: We did!

Student: Yeah, we did!

Lecturer: You've actually taken notes?

Student: Yeah.

Lecturer: And you did that?

Student: Yeah.

Lecturer: Right! Wonderful! I was just a little curious

At other times several patterns co-occur, as in the excerpt below which contains all the four patterns mentioned above within the same follow-up move: repetition of the student's response, literal positive remark (good), forms of acceptance (right, yeah) and two different hyperbolic evaluative expressions. 
(11) Text KLW

Teacher: When you pass. Erm, right. I'll just write this down. Okay, if you'd like to try that. Add that up. Six point eight plus.

Student: Nought point O two.

Teacher: Nought point 0 two. Good, yeah, that's great. Right, that's brilliant. I think you can do decimals.

\section{CONCLUSION}

Although limited to hyperbole, this paper aimed at addressing a crucial limitation in our understanding of non-literal language, namely the production of figures of speech in terms of function and placement within exchanges. Rather than addressing hyperbole comprehension, I have examined the production of exaggeration in naturally-occurring learning encounters. Thus, this paper adheres to the view that for a thorough study of figures the investigation of psychological factors should be complemented with research on their process of production.

Probably the most important finding in the study is that within the teaching exchange system hyperbole is mainly found in follow-up moves rather than initiating or response moves. This means that exaggeration typically occurs in IRF exchanges - the most characteristic exchange in traditional teaching (Sinclair and Coulthard, 1975) - as opposed to other type of exchanges. The results also point out that hyperbole is primarily evaluative in learning encounters. Since other functions remain subsidiary, one cannot but emphasise the central role the affective dimension plays in the production and reception of hyperbole. Not in vain, evaluation has often been identified as a prominent function of this figure in the literature on the subject.

Although in their study of the functions of figurative language Roberts and Kreuz (1994) found that exaggeration was more frequently used to convey negative emotions than positive affect, the BNC texts examined show a different pattern. Positive hyperbolic remarks exceed by far negative ones. Teachers in our data showed approval, rarely criticism, when engaged in hyperbole. This is consistent with Sell et al.'s (1997) study of parents' use of non-literal language with pre-school children where the only type of evaluation attributed to hyperbole is positive. This might suggest that there is something in common between parent-children exchanges and teacher-students interaction. In this sense, Tsui (1994) notes that in follow-up moves, an evaluation of the correctness of the response typically occurs in classroom exchanges, quiz exchanges and mother-child exchanges.

I do not wish to claim that all evaluative forms in follow-up moves are realised through hyperbole but when exaggeration is found in learning encounters it is primarily used to evaluate the students' reply. This explains that, with a few exceptions, all hyperbolic utterances in our data were produced by the teacher. That is not only due to the fact that the teacher has more opportunities to talk but also because of the role of hyperbole in instruction: it is used to evaluate and that is the teacher's task and privilege, not the student's.

This evaluative feedback move is one of the main differences between natural conversation and classroom interaction. In most other social interactions, no participant is 
specified as having the automatic right to impose judgement on the other's behaviour (Carroll et al., 1992). Tsui (1994) claims that the follow-up move has a general function of acknowledging the outcome of the interaction and that to evaluate the correctness of the response is only one of the realisations of this function. She notes that other realisations are «to accept the outcome of the preceding interaction, to show an appreciation of the response, to minimize the face damage that has been done, to show a change of state of knowledge,...» (p. 41). In this sense, it would be interesting to analyse the placement and functions of hyperbole in natural conversation to compare and contrast the results with the study of learning encounters.

The notion of follow-up and feedback move is closely related to the more general concept of feedback in class. Apart from general instruction, the provision of feedback is considered to be the primary role of teachers. Feedback can be positive, when it confirms the correctness of the original behaviour, or negative, if it indicates that the original behaviour is not correct (Carroll et al., 1992). Feedback involving exaggeration in our data was mainly evaluative and judgemental rather than descriptive of the specific task or response. It tended to be affective, primarily reflecting what was good about the student's work or praising the learner's effort and attitude.

\section{REFERENCES}

Aston, Guy and Lou Burnard (1998). The BNC Handbook: Exploring the British National Corpus with SARA, Edinburgh, Edinburgh University Press.

Brazil, David et al. (1980). Discourse Analysis and Language Teaching, London, Longman.

Cacciari, Christine (1998). «Why Do We Speak Metaphorically? Reflections in Thought and Language». In Katz, Albert N. et al. (eds.) Figurative Language and Thought, Oxford, Oxford University Press, 119-157.

Cano Mora, Laura (2011). This Book Will Change Your Life! Hyperbole in Spoken English, Valencia, Publicacions de la Universitat de València.

CArroll, Susanne et al. (1992). «The Role of Feedback in Adult Second Language Acquisition: Error Correction and Morphological Generalizations», Applied Psycholinguistics, 13, 173-198.

Carter, Ronald A. and Michael J. McCarthy (1997). Exploring Spoken English, Cambridge, Cambridge University Press.

Cohen, Raymond (1987). «Problems of Intercultural Communication in Egyptian-American Diplomatic Relations», International Journal of Intercultural Relations, 11, 29-47.

Colston, Herbert L. and Shauna B. Keller (1998). «You'll Never Believe This: Irony and Hyperbole in Expressing Surprise», Journal of Psycholinguistic Research, 27, 499-513.

Colston, Herbert L. and Jennifer O'Brien (2000). «Contrast and Pragmatics in Figurative Language: Anything Understatement Can Do, Irony Can Do Better», Journal of Pragmatics, 32, 1557-1583.

Coulthard, Malcolm (1977). An introduction to Discourse Analysis, London, Longman.

EDELman, Robert J. et al. (1989). «Self-Reported Expression of Embarrassment in Five European Cultures», Journal of Cross-Cultural Psychology, 20, 357-371.

Ellis, Rod (1994). The Study of Second Language Acquisition, Oxford, Oxford University Press.

FALK, Lilian (1990). «Between Emphasis and Exaggeration: Verbal Emphasis in the English of Cape Breton Island». In Black, Jim (ed.) Papers from the Fourteenth Annual Meeting of the Atlantic Provinces Linguistic Association, St. John's Memorial, University of Newfoundland, 39-49. 
Fontanier, Pierre ([1830] 1969). Les figures du discours, Paris, Flammarion.

Hutchby, Ian and Paul Drew (1995). «Conversation Analysis». In Verschueren, Jef et al. (eds.) Handbook of Pragmatics: Manual, Amsterdam, John Benjamins, 182-189.

KATZ, Albert N. (1996). «On Interpreting Statements as Metaphor or Irony: Contextual Heuristics and Cognitive Consequences». In Mio, Jeffery S. and Albert N. Katz (eds.) Metaphor: Implications and Applications, Mahwah NJ, Lawrence Erlbaum Associates, 1-22.

Kreuz, Roger J. et al. (1996). «Figurative Language Occurrence and Co-Occurrence in Contemporary Literature». In Kreuz, Roger J. and Mary S. MacNealy (eds.) Empirical Approaches to Literature and Aesthetics, Norwood NJ, Ablex Publishing Corporation, 83-97.

- (1998). «The Use of Exaggeration in Discourse: Cognitive and Social Facets». In Fussell, Susan R. and Roger J. Kreuz (eds.) Social and Cognitive Approaches to Interpersonal Communication, Mahwah NJ, Lawrence Erlbaum Associates, 91-111.

McCarthy, Michael J. (1998). Spoken Language and Applied Linguistics, Cambridge, Cambridge University Press.

Poster, Carol (2000). «Being, Time, and Definition: Toward a Semiotics of Figural Rhetoric», Philosophy and Rhetoric, 33, 116-136.

Ravazzoli, Flavia (1978). «I meccanismi linguistici dell'iperbole». In Santini, L. Ritter and Ezio Raimondi (eds.) Retorica e critica letteraria, Bolonia, Il Mulino, 69-86.

Roberts, Richard M. and Roger J. Kreuz (1994). «Why Do People Use Figurative Language?», Psychological Science, 5, 159-163.

SADock, Jerrold M. (1993). «Figurative Speech and Linguistics». In Ortony, Andrew (ed.) Metaphor and Thought, $2^{\text {nd }}$ edition, Cambridge, Cambridge University Press, 42-57.

Schmitт, Norbert (2000). Vocabulary in Language Teaching, Cambridge, Cambridge University Press.

Sell, Marie A. et al. (1997). «Parents' Use of Nonliteral Language with Preschool Children», Discourse Processes, 23, 99-118.

Sinclair, John McH. and R. Malcolm Coulthard (1975). Towards an Analysis of Discourse, Oxford, Oxford University Press.

SPITZBARDT, Harry (1963). «Overstatement and Understatement in British and American English», Philologica Pragensia, 6, 277-286.

STRÄSSLER, Jürg (1982). Idioms in English: A Pragmatic Analysis, Tübingen, Narv.

Stubbs, Michael (1983). Discourse Analysis: The Sociolinguistic Analysis of Natural Language, Oxford, Basil Blackwell.

- (1996). Text and Corpus Analysis: Computer-Assisted Studies of Language and Culture, Oxford, Basil Blackwell.

Swales, John M. (1990). Genre Analysis: English in Academic and Research Settings, Cambridge, Cambridge University Press.

Swartz, Marc J. (1976). «Hyperbole, Politics and Potent Specifications: The Political Uses of a Figure of Speech». In O'Barr, William M. and Jean F. O'Barr (eds.) Language and Politics, The Hague, Mouton, 101-116.

Tsui, Amy B. M. (1994). English Conversation, Oxford, Oxford University Press.

Zwicky, Arnold M. and Jerrold M. SADOCK (1975). «Ambiguity Tests and How to Fail Them». In Kimball, John P. (ed.) Syntax and Semantics 4, New York, Academic Press, 1-36. 